\title{
Market Reactions to ECB Policy Innovations: A Cross-Country Analysis
}

Fausto Pacicco

Luigi Vena Andrea Venegoni 
Collana: Università Cattaneo Working Papers

ISSN: 2532-554X

Università Carlo Cattaneo - LIUC

Corso Matteotti 22, 21053 Castellanza (VA), Tel. 0331-572.282, email: biblio@liuc.it 


\title{
Market Reactions to ECB Policy Innovations: A Cross-Country Analysis
}

\author{
Fausto Pacicco*, Luigi Vena*, Andrea Venegoni*
}

\begin{abstract}
Financial markets vest an important role both in conveying monetary policy innovations to the real economy and in shaping business cycle's fluctuations. Hence, it becomes crucial to assess whether the ECB is able to wield homogeneous reactions in the main Eurozone stock markets and to quell their turbulences. The empirical analysis shows that conventional policy rate shifts affect unevenly the equity indices of the countries analysed, generating asymmetries between their business cycles. Moreover, the ECB stance proved unable to weather the storm and trigger an economic recovery. This calls for a refinement of ECB conduct and justifies the extensive employment of unconventional measures to revive the economy.
\end{abstract}

Jel code: E42, E52, E58, F42, F45, G14

Keywords: Monetary Policy Transmission, European Monetary Union, Financial Markets, Event Study

\section{Introduction}

The relationship between monetary policy and equity markets has remained in the background of the mainstream debate, as they never constituted a central target of the policy stance and their role in channelling the authorities' interventions was always considered marginal. The occurrence of the financial crises that have affected the global economy since 2007/2008 has contributed to change this belief and made emerge the relevance of financial markets fluctuations for the central banking activity. There are three dimensions that connect stock markets to monetary policy: firstly, they contribute to convey the authorities' interventions to the economy; secondly, they serve as a tool through which is possible to monitor the impact of the policy stance in the short term; thirdly, to keep financial markets under control, helping to quell and steer their boom and bust cycles, is gaining importance in the agenda of central bankers (Smets, 2013).

Indeed, monetary policy objective is to achieve and maintain a target level in the main macroeconomic variables such as production, prices and unemployment. However, for policy actions to influence such final target variables it takes some time and, in the meanwhile, it might be worth for the authority to monitor whether the effects of its manoeuvres are going in the right direction. In order to do this, one possibility is to

* LIUC - Università Cattaneo, fpacicco@liuc.it, Ivena@liuc.it, avenegoni@liuc.it 
evaluate how financial markets respond, being equity and asset prices the economic items that react more promptly to such innovations. Besides, these variables play a decisive role in the transmission mechanism; recent literature started to consider them constituents of a primary channel through which the monetary stance is conveyed to the economy (Bruno and Shin, 2015, Altunbas et al. 2010).

In addition to this, financial markets behaviour has increasingly become, well before the 2007 financial crisis, a reason of concern for the regulators worldwide. This is because their fluctuations, their boom and bust stages, have significantly contributed in shaping the business cycles of developed countries in the last forty years, sometimes generating, especially in the bust phase, enduring ominous effects that persisted for long time and needed extraordinary policy measures to be overcome. Along with a sound regulatory structure, that helps to limit the risk exposure of banks and corporations, the adoption of transparent and reliable accounting systems, a rigorous supervisory activity and coherent fiscal policies, an adequate monetary policy is fundamental to avoid that prerequisites of disastrous crises form on the financial markets (Stein, 2012).

As Bernanke and Gertler (1995) highlight, asset price crashes have done sustained damage to the economy only in cases when monetary policy remained unresponsive or actively reinforced deflationary pressures. Neither the 2007 financial crises nor the European 2011 sovereign debt one, as many argue, made exception to this claim.

Hence, it becomes relevant to assess how financial markets react to monetary policy innovations on three accounts, two linked to the central banks' standard activity of monetary policy setting and one connected to the role of financial market supervisor, that is gaining importance in the agenda of monetary authorities: the former two, which will give to the regulator insights on the direction of its policy interventions and on the functioning of a relevant channel of the transmission mechanism, while the latter will help to learn how monetary actions can affect the market and quell its excesses.

In their seminal paper Bernanke and Kuttner (2005) analyse the effect of policy surprises on the U.S. equity markets, finding that monetary innovations lead to sizeable and significant modifications in the stock market performances. Following the same line of research, Rigobon and Sack (2002), Ehrmann and Fratzscher (2004) and Ioannidis and Kontonikas (2006) conduct comparable researches, the first two replicating Bernanke and Kuttner (2005) analyses with alternative measures of market expectations of Federal Reserve conduct, while the latter extending the scope of the 
exam to thirteen OECD countries, and hence providing an international benchmark of the influence that monetary actions can have on stock indices and, hence, equity markets.

Our analysis follows the track set by these previous works aiming to assess the reaction of the principal Eurozone equity markets to a revision of the main refinancing rate operated by the European Central Bank (ECB henceforth). In particular, the questions to which this research would like to answer are the following: do financial markets of EMU countries have symmetric reactions to conventional monetary policy innovations (i.e. interest rate shifts)? Does the pattern of those responses show signs of convergence as time passed by and the economies adapted to the new, unified monetary policy? Are these conventional tools sufficient to exploit the task to govern financial markets?

These are relevant questions that have to be answered, as from the inception of the currency union several doubts were casted around its feasibility and especially about the ability of the unified central bank to tame such a heterogeneous pool of economic systems, characterized by very different industrial structures and business cycles that do not seem to follow the same track (Bayoumi and Eichengreen, 1993, Ehrmann et al., 2003).

A lot of research was produced in order to shed light on the ability of the ECB to guarantee a synchronous unwinding of the Eurozone business cycle. These research efforts concentrated mainly on assessing the degree of heterogeneity of different channels of the transmission mechanism and their impact on the target variables (for a summary of the results see Chatelain et al., 2003 and Ehrmann et al. 2003) disregarding the role that financial markets play in the transmission mechanism of monetary policy innovations and forgetting their central role as policy signals.

Since financial markets constitute an important milestone for monetary regulators, our analysis aims at understanding whether the stock indices of the various members of the currency union react homogeneously.

To achieve our goal, differently from the methodological approach applied in the works above cited, we resort to an event study methodology to appreciate the reactions of the main Eurozone equity indices to ECB target rate modifications in each of the forty dates in which an effective shift of the main refinancing rate was operated. The adoption of the event study methodology brings a twofold benefit: firstly, it allows to identify and value the patterns of each country's stock index reaction to policy 
manoeuvres, appreciating its evolution during time and permitting us to assess whether Eurozone equity markets experienced a convergence in their response to ECB innovations; secondly, through it is also possible to evaluate whether the policy stance served to achieve the financial market stabilization task of the ECB, helping the markets to absorb the shots blown by the two crises. The stock indices considered are the ones of Belgium, France, Germany, Greece, Italy, the Netherlands, Portugal and Spain, which represent the main economies of the currency union and also the main members of the two different economic groups in the Eurozone: the "core countries", and the "periphery".

The evidences gathered suggest that some asymmetries show up immediately in the different cross-country reaction of the main national equity indices. In the pre-crisis period these reactions displayed a very high degree of heterogeneity. They show some convergence in the two crises subperiods, even if their magnitude remains different at an aggregate level, with the "core" group displaying a higher and more frequent reaction to the policy stance until the occurrence of the sovereign-debt crisis, when is the "peripheral" group the more affected by rate shifts.

On the market stabilization standpoint, it appears that conventional policies implemented do not suffice by themselves to dampen the high volatility and restore the capital markets well-functioning before hitting the zero lower bound. This is surely due to the harshness of the shocks that have consecutively hit the eurozone economies, but some role could also be played by the insufficient strength and the delayed timing in the ECB's intervention.

This clearly sends the message that additional efforts must be put in the synchronization of the eurozone business cycles, which still display a severe structural incoherence, bringing their equity markets to react heterogeneously to the monetary policy stance. Moreover, conventional tools appear as not sufficient to govern financial markets when such severe shocks hit them, hence justifying the extensive employment of unconventional measures adopted by the ECB.

\section{The Model}

The choice to implement an event study framework and hence divert from the track set in the previous literature is dictated by the will to have a picture of each country's stock market reaction every time a shift in the main target rate was operated by the ECB. This is not possible holding a linear regression or VAR approach, as these two tools 
only allow to identify the average impact of monetary actions on the variables under examination in the timespan considered.

According to neoclassical rational expectations paradigm, to distinguish between the expected and unexpected component of policy innovations is of extreme importance, as the market is unlikely to respond to the ones already anticipated. Hence, doing this becomes a compulsory step in order to carry out a rigorous analysis. (Bernanke and Kuttner, 2005).

Thus, as the effects of an event are bound to be immediately reflected in security prices, it is necessary to employ a technique able to identify whether abnormal returns (ARs) are generated on a certain date or interval (McKinlay, 1997).

The event study methodology is well suited to such analysis, as it fits the prerequisites aforementioned. Moreover, assessing whether a monetary policy shock generates ARs on stock markets provides a punctual measure of the strength of the influence that the central bank can exert on them, giving a picture of how regulator's ability to steer markets trends evolves over time.

Between the many possible specification of such an econometric tool, the historical mean model seems the more adequate to our case. Indeed the use of a market model may be detrimental to our analysis, for at least two reasons:

the 8 indices under scrutiny cover almost entirely the Euro-denominated stock market, thus we may have endogeneity issues, if we use a Euro-denominated stock index (e.g. the EuroStoxx Index);

if we resort to an international index, we may bias our estimates because of a currency effect and of a country-specific effect: the former should emerge, especially in case of a "base currency" index, since currencies are one of the major movers of financial markets; the latter may ruin our analysis since the peculiarities of each market, due to the different structure by their specific sectors, may not be adequately taken into account.

Thus, adopting the historical mean model we overcome the currency effect, being respectful of the several market structures, without loss of severity: Brown and Warner $(1980,1985)$ point out that the results of these two models do not systematically differ.

Moreover, it fits our analysis allowing to control for the different industry compositions of the various country indices. Indeed, if we employ the market model, we shall control for the different composition of the country indices and the selected benchmark, given 
that (i) the ARs are calculated as the spread between the event window return and the historical mean return of the same index and (ii) the sectoral composition of the equity indices considered does not display a significant time variation.

According to this framework, the ARs is computed as the spread between the actual ex-post return of the security over the event window and its normal return over the same window. The normal return is defined as the expected return without conditioning on the event taking place. In algebraic terms:

$A R_{i, t}=R_{i, t}-\overline{R_{i, t}}$

Where $A R_{i, t}$ identifies the abnormal return of stock index $i$ on date $t$, with $i=\{$ Belgium, France, Germany, Greece, Italy, Netherlands, Portugal, Spain\}; $R_{i, t}$ is the log-return of index $i$ on date $t, \overline{R_{i, t}}$ is the average return of the $i$-th index over the estimation window.

As the time-span considered is quite extended and, in it, exogenous shocks have hit the eurozone, altering the dynamics of the economic cycle and of the financial markets (as shown in Serati and Venegoni, 2017), the average returns of the equity indices were susceptible to changes. Thus, we divide the sample into five different segments, corresponding to as many estimation windows (all of equal length), each of them used to calculate the abnormal returns of the events included in their relative time-segment. As prescribed by theory, in order to exclude the observations near the event days and the event date itself, the estimation windows are obtained uniting the observations that are not in the range of plus and minus twenty days from each rate modification.

As event window, we consider only the day in which the policy decision is announced to the market, following the standard approach held in the literature, given the assumption that rational and liquid markets, like those under scrutiny, react immediately to new information, incorporating it in the prices in a very short time ${ }^{1}$.

\footnotetext{
${ }^{1}$ We have computed abnormal returns even on longer event windows, to control for delayed reactions or information leakages. In both cases evidence brought us to deny these occurrences and suggested that the optimum event window to consider was the one we present.
} 


\section{Results}

\subsection{Sample selection and event study setting}

The timespan of our analysis goes from June 1999 to June 2016, covering all but the first two policy decisions undertaken by the ECB. Since we use the future rate of threemonths Euribor ${ }^{2}$, which time series starts form June 1999, to proxy market expectations we have two drop the first two policy decisions.

The variables considered in our analysis (reported in table 1) include the equity indices of the main economies in the Eurozone, selected in order to represent the two economic areas that characterise the currency union, id est the core and the peripheral group.

Table 1. List of variables per country

\begin{tabular}{|l|l|}
\hline Variable Name & Country \\
\hline ECB Main refinancing rate & -- \\
\hline Euribor 3-Month Future rate & -- \\
\hline BEL 20 Index & Belgium \\
\hline CAC 40 Index & France \\
\hline DAX 30 Index & Germany \\
\hline ASE General Index (ASE) & Greece \\
\hline FTSE MIB Index & Italy \\
\hline AEX Index & The Netherlands \\
\hline PSI 20 Index & Portugal \\
\hline Ibex 35 Index & Spain \\
\hline
\end{tabular}

List of variables included in the analysis with their country of reference.

\footnotetext{
${ }^{2}$ We are conscious of the fact that the debate on how to obtain a proxy measure of the ECB policy rate is open and many other rates or tools have been adopted. For this reason, we have conducted some robustness check, both with other market rates and indicators obtained from surveys. With all of them we obtain results that are very similar to the ones presented.
} 
The sample includes 4293 daily observations for the eight country indices considered and the two portfolios (Core and Non-Core countries) in which we group them. The use of daily stock returns ${ }^{3}$, with their implied features, does not impair the effectiveness and reliability of an event study based on the OLS market model or the historical mean model, as the non-normality of stock and excess returns and their autocorrelation does not affect the statistical power of the methodology (Brown and Warner, 1985).

As can be seen from table 2, out of forty modifications of the policy rate in these seventeen years, sixteen times $(25 \%)$ the market was able to anticipate them (unexpected modification less than $10 \%$ of the actual rate change), while twenty-four times $(75 \%)$ the regulator surprised the public ${ }^{4}$.

Looking at the temporal succession of expected and unexpected interventions, is possible to notice that main Eurozone equity markets took some time to adapt to the new regulatory stance but then, from March 2006 to October 2008, before the subprime crisis, the regulator never surprised the public, that was able to predict its rate modifications almost perfectly. The mean and standard deviation of unexpected rate shifts is, indeed, the lowest in the pre-crisis period, as is shown in table 3 . Then, we observe a spike in the uncertainty of market players, reflected in an increase in the average difference between the effective rate shift and the one predicted by the market. This can evidence the fact that the ECB reaction to the explosion of the financial turmoil was not in line with the expectations, as it appears that agents considered the approach held as too mild to counteract the negative pressures driving downwards the Eurozone economies.

\footnotetext{
${ }^{3}$ Returns are continuously compounded.

${ }^{4}$ We have computed the ratio between the unexpected and actual policy rate change in order to understand whether the market was able to read the regulator's intentions ex-ante. This is because, as in the last part of the sample the target rate level was approaching the zero lower bound, to consider the absolute discrepancy between the actual and unexpected change could lead to overestimate the ability of the market to predict the regulators manoeuvres.
} 
Table 2. ECB rates levels and modifications: actual and unexpected

\begin{tabular}{|c|c|c|c|c|c|}
\hline $\begin{array}{l}\text { Decision } \\
\text { Date }\end{array}$ & $\begin{array}{l}\text { ECB } \\
\text { Target } \\
\text { Rate } \\
\text { Level }\end{array}$ & $\begin{array}{l}\text { ECB Rate } \\
\text { Modification }\end{array}$ & $\begin{array}{l}\text { Euribor } \\
\text { Three } \\
\text { Months } \\
\text { Future Rate } \\
\text { Variation }\end{array}$ & $\begin{array}{l}\text { Unexpec } \\
\text { ted Rate } \\
\text { Modifica } \\
\text { tion }\end{array}$ & $\begin{array}{l}\text { Ratio between } \\
\text { unexpected and } \\
\text { effective rate } \\
\text { modification }\end{array}$ \\
\hline $04 / 11 / 1999$ & $3 \%$ & $0,50 \%$ & $0,24 \%$ & $0,26 \%$ & $52,00 \%$ \\
\hline 03/02/2000 & $3,25 \%$ & $0,25 \%$ & $0,37 \%$ & $-0,12 \%$ & $-48,00 \%$ \\
\hline $16 / 03 / 2000$ & $3,50 \%$ & $0,25 \%$ & $0,31 \%$ & $-0,06 \%$ & $-24,00 \%$ \\
\hline 27/04/2000 & $3,75 \%$ & $0,25 \%$ & $0,23 \%$ & $0,02 \%$ & $8,00 \%$ \\
\hline 08/06/2000 & $4,25 \%$ & $0,50 \%$ & $0,37 \%$ & $0,13 \%$ & $26,00 \%$ \\
\hline $31 / 08 / 2000$ & $4,50 \%$ & $0,25 \%$ & $0,43 \%$ & $-0,18 \%$ & $-72,00 \%$ \\
\hline $05 / 10 / 2000$ & $4,75 \%$ & $0,25 \%$ & $0,16 \%$ & $0,09 \%$ & $36,00 \%$ \\
\hline $10 / 05 / 2001$ & $4,50 \%$ & $-0,25 \%$ & $-0,45 \%$ & $0,20 \%$ & $-80,00 \%$ \\
\hline 30/08/2001 & $4,25 \%$ & $-0,25 \%$ & $-0,31 \%$ & $0,06 \%$ & $-24,00 \%$ \\
\hline 17/09/2001 & $3,75 \%$ & $-0,50 \%$ & $-0,47 \%$ & $-0,03 \%$ & $6,00 \%$ \\
\hline 08/11/2001 & $3,25 \%$ & $-0,50 \%$ & $-0,45 \%$ & $-0,05 \%$ & $10,00 \%$ \\
\hline 05/12/2002 & $2,75 \%$ & $-0,50 \%$ & $-0,45 \%$ & $-0,05 \%$ & $10,00 \%$ \\
\hline 06/03/2003 & $2,50 \%$ & $-0,25 \%$ & $-0,35 \%$ & $0,10 \%$ & $-40,00 \%$ \\
\hline 05/06/2003 & $2 \%$ & $-0,50 \%$ & $-0,40 \%$ & $-0,10 \%$ & $20,00 \%$ \\
\hline 01/12/2005 & $2,25 \%$ & $0,25 \%$ & $0,30 \%$ & $-0,05 \%$ & $-20,00 \%$ \\
\hline 02/03/2006 & $2,50 \%$ & $0,25 \%$ & $0,25 \%$ & $0,00 \%$ & $0,00 \%$ \\
\hline 08/06/2006 & $2,75 \%$ & $0,25 \%$ & $0,25 \%$ & $0,00 \%$ & $0,00 \%$ \\
\hline 03/08/2006 & $3 \%$ & $0,25 \%$ & $0,26 \%$ & $-0,01 \%$ & $-4,00 \%$ \\
\hline 05/10/2006 & $3,25 \%$ & $0,25 \%$ & $0,26 \%$ & $-0,01 \%$ & $-4,00 \%$ \\
\hline 07/12/2006 & $3,50 \%$ & $0,25 \%$ & $0,20 \%$ & $0,05 \%$ & $20,00 \%$ \\
\hline 08/03/2007 & $3,75 \%$ & $0,25 \%$ & $0,23 \%$ & $0,02 \%$ & $8,00 \%$ \\
\hline 06/06/2007 & $4 \%$ & $0,25 \%$ & $0,24 \%$ & $0,01 \%$ & $4,00 \%$ \\
\hline 03/07/2008 & $4,25 \%$ & $0,25 \%$ & $0,23 \%$ & $0,02 \%$ & $8,00 \%$ \\
\hline 08/10/2008 & $3,75 \%$ & $-0,50 \%$ & $-0,70 \%$ & $0,20 \%$ & $-40,00 \%$ \\
\hline 06/11/2008 & $3,25 \%$ & $-0,50 \%$ & $-0,81 \%$ & $0,31 \%$ & $-62,00 \%$ \\
\hline 04/12/2008 & $2,50 \%$ & $-0,75 \%$ & $-0,76 \%$ & $0,01 \%$ & $-1,33 \%$ \\
\hline 15/01/2009 & $2 \%$ & $-0,50 \%$ & $-0,61 \%$ & $0,11 \%$ & $-22,00 \%$ \\
\hline 05/03/2009 & $1,50 \%$ & $-0,50 \%$ & $-0,67 \%$ & $0,17 \%$ & $-34,00 \%$ \\
\hline 02/04/2009 & $1,25 \%$ & $-0,25 \%$ & $-0,01 \%$ & $-0,24 \%$ & $96,00 \%$ \\
\hline 07/05/2009 & $1 \%$ & $-0,25 \%$ & $-0,06 \%$ & $-0,19 \%$ & $76,00 \%$ \\
\hline 07/04/2011 & $1,25 \%$ & $0,25 \%$ & $0,38 \%$ & $-0,13 \%$ & $-52,00 \%$ \\
\hline 07/07/2011 & $1,50 \%$ & $0,25 \%$ & $0,28 \%$ & $-0,03 \%$ & $-12,00 \%$ \\
\hline 03/11/2011 & $1,25 \%$ & $-0,25 \%$ & $-0,75 \%$ & $0,50 \%$ & $-200,00 \%$ \\
\hline 08/12/2011 & $1,00 \%$ & $-0,25 \%$ & $-0,14 \%$ & $-0,11 \%$ & $44,00 \%$ \\
\hline 05/07/2012 & $0,75 \%$ & $-0,25 \%$ & $-0,33 \%$ & $0,08 \%$ & $-32,00 \%$ \\
\hline 02/05/2013 & $0,50 \%$ & $-0,25 \%$ & $-0,06 \%$ & $-0,19 \%$ & $76,00 \%$ \\
\hline 07/11/2013 & $0,25 \%$ & $-0,25 \%$ & $0,03 \%$ & $-0,22 \%$ & $88,00 \%$ \\
\hline 05/06/2014 & $0,15 \%$ & $-0,10 \%$ & $-0,04 \%$ & $-0,06 \%$ & $60,00 \%$ \\
\hline 04/09/2014 & $0,05 \%$ & $-0,10 \%$ & $-0,13 \%$ & $0,03 \%$ & $-30,00 \%$ \\
\hline 10/03/2016 & $0,00 \%$ & $-0,05 \%$ & $0,28 \%$ & $-0,33 \%$ & $660,00 \%$ \\
\hline
\end{tabular}

European Central Bank main refinancing rate level, its modification, future on the interbank rate modification, and the gap between the official rate and market forecasts (source: ECB and Bloomberg) 
As four out of the first five rate cuts operated after the crisis burst fell short of market expectations of a more aggressive easing of the policy stance. The uncertainty around the central bank policy persisted and even increased in the sovereign-debt crisis period, where we observe both the highest mean and standard deviation of the discrepancy between the effective policy decision and the market expectations.

Table 3. Mean of absolute values and standard deviation of unexpected policy rate change for each sub-sample period

\begin{tabular}{|l|l|l|}
\hline Sub-sample period & Mean & Standard Deviation \\
\hline Pre-crisis period & $0,07 \%$ & $0,10 \%$ \\
\hline Financial crisis period & $0,15 \%$ & $0,19 \%$ \\
\hline Sovereign-Debt crisis period & $0,19 \%$ & $0,25 \%$ \\
\hline
\end{tabular}

Mean and standard deviation of unexpected policy manoeuvres. The mean is computed on the absolute values of the rate change surprise.

Thus, it seems interesting to see whether the reaction of the main eurozone equity markets has changed in these three different periods and if these differences evidence a modification of the transmission channel that has some policy relevance. In order to do this we observe the results obtained through the employment of the event study framework.

\subsection{Empirical evidence}

The results yielded by the event study, shown in Table 4, suggest that different patterns of reaction to monetary policy shocks can be highlighted for the Eurozone countries. In particular, Core countries (Belgium, France, Germany and the Netherlands) show a higher reactivity to the new policy stance than the other countries in the period that goes from the institution of the EMU to the eve of the 2008 financial crisis, while Non-core countries (Greece, Italy, Spain and Portugal) appear more reactive in the aftermath of the sovereign debt crisis.

This constitutes an interesting piece of evidence: countries considered to be amongst the leading economies of the currency union have equity markets that are more affected by the monetary decisions than the others.

The country by country analysis reveals that the German Dax index is the one that displays more significant reactions (14), followed by a group that encompasses the 
indices of France (13), Italy (13), Belgium (12), Spain (11) and the Netherlands (11). It is interesting to note that the indices of the two weaker economies considered, Portugal and Greece, display markedly less significant reactions, respectively 8 and 7 . This hints that the equity markets transmission channel did not work in the same way for all the Eurozone countries but, rather, was perceived by financial agents as not adequate for the needs of the weakest economies in the currency area.

It is, hence, necessary to focus the analysis by decomposing the sample in three different time periods. Using the dates in which the 2008 financial crises and the sovereign debt crises unleashed their effects on the Eurozone economies, we aim to gain further comprehension of the links between national equity markets and ECB actions.

In the first subsample, from April, $8^{\text {th }} 1999$ to July, $3^{\text {rd }} 2008$, the equity markets do not seem to display a harmonized reaction to central bank's decisions, as only on three occasions (out of twenty-four) more than half of the indices display an abnormal return simultaneously. Again, this might be due to the necessity of market agents to adapt to ECB's conduct and acquire a sufficiently extended track record on which basing their expectations.

By analysing the second subsample, which considers the period of the financial crisis contagion from the U.S. market bringing the contagion to the Eurozone. From the rate modification occurred on October, $8^{\text {th }}, 2008$, to the one of July, $7^{\text {th }} 2011$, coincident reactions appear in the first two decisions, and then for the ones of March and April 2009. In three of these four dates all the indices reacted significantly and accordingly, a fact never registered before and never repeated afterwards. Thus, it appears that in these first three dates (October $8^{\text {th }}, 2008$, November $6^{\text {th }}, 2008$ and March $5^{\text {th }} 2009$ ) the equity indices display a strong and significant negative reaction, as the rate modification operated by the ECB was not going in the same direction (first case) or was deemed as too moderate (second and third case) given the circumstances. In the fourth case (April $2^{\text {nd }}, 2009$ ) all the markets showed positive significant reactions as the ECB proceeded to a $0,5 \%$ rate cut that was unexpected, given the conservative behaviour held until then, and committing to a resolute expansionary conduct until the exit from the turmoil. 
These findings support the claim that the ECB's reaction to the first crisis was not as solicit and marked as it should have been or, at least, as the financial markets wanted it to be, since the regulator took too much time to understand the magnitude of the phenomenon. This provides us with some evidence related to the ability of monetary policy to govern financial markets and quell them when necessary, as it seems that, at least in this occasion, the ECB did not succeed in prompting immediately an adequate reaction.

Lastly, for what concerns the sovereign debt crisis period, the first thing that is worth to notice is that the Greek equity market cease to react, probably as its economy was already stuck in an irreversible crisis and, hence, was distant from the dynamics affecting the rest of the Eurozone.

Table 4. Abnormal returns registered on single country indexes and on core and non-core areas on the ECB announcement of rate's modification

\begin{tabular}{|c|c|c|c|c|c|c|c|c|c|c|c|}
\hline Date & URM & BE & FR & DE & GR & IT & NL & PT & ES & Core & Non-Core \\
\hline 04/11/99 & $0,26 \%$ & $1,82 \%$ * & $0,61 \%$ & $1,42 \%$ & $-0,36 \%$ & $1,41 \%$ & $0,44 \%$ & $1,12 \%$ & $1,88 \%$ & $-0,03 \%$ & $1,07 \%$ \\
\hline 03/02/00 & $-0,12 \%$ & $3,53 \%$ *** & $3,43 \%$ *** & $2,59 \%$ * & $1,62 \%$ & $2,19 \%$ * & $1,94 \%$ * & $2,18 \%$ ** & $3,18 \%$ ** & $1,07 \%$ & 0,99\% \\
\hline $16 / 03 / 00$ & $-0,06 \%$ & $6,62 \%$ *** & $1,20 \%$ & $2,34 \%$ & $4,37 \%$ ** & $1,81 \%$ & $0,85 \%$ & $-0,51 \%$ & $-0,03 \%$ & $2,87 \% \%^{* * *}$ & $2,28 \%$ ** \\
\hline $27 / 04 / 00$ & $0,02 \%$ & $-1,57 \%$ & $-2,18 \%$ * & $-2,20 \%$ & $2,38 \%$ & $-0,78 \%$ & $-0,94 \%$ & $-1,07 \%$ & $-1,71 \%$ & $2,75 \%$ *** & $1,39 \%$ \\
\hline 08/06/00 & $0,13 \%$ & $-1,39 \%$ & $0,47 \%$ & $-0,60 \%$ & $0,83 \%$ & $-0,42 \%$ & $1,58 \%$ & $0,56 \%$ & $1,15 \%$ & $-1,72 \% *$ & $-0,31 \%$ \\
\hline $31 / 08 / 00$ & $-0,18 \%$ & $-0,02 \%$ & $-0,06 \%$ & $0,51 \%$ & $3,60 \%$ * & $1,20 \%$ & $1,46 \%$ & $0,74 \%$ & $0,26 \%$ & $0,01 \%$ & $0,51 \%$ \\
\hline 05/10/00 & $0,09 \%$ & $0,22 \%$ & $0,70 \%$ & $1,09 \%$ & $-1,36 \%$ & $0,20 \%$ & $0,74 \%$ & $-1,78 \%$ * & $0,81 \%$ & $0,47 \%$ & $1,43 \%$ \\
\hline $10 / 05 / 01$ & $0,20 \%$ & $1,48 \%$ & $2,14 \%$ * & $1,74 \%$ & $-0,10 \%$ & $1,26 \%$ & $1,14 \%$ & $0,87 \%$ & $1,43 \%$ & $0,69 \%$ & $-0,55 \%$ \\
\hline $30 / 08 / 01$ & $0,06 \%$ & $-0,26 \%$ & $-2,67 \%{ }^{* *}$ & $-2,64 \%{ }^{*}$ & $-0,29 \%$ & $-1,97 \%$ & $-1,99 \%$ * & $-0,71 \%$ & $-2,20 \%$ & $1,62 \%$ & $0,85 \%$ \\
\hline $17 / 09 / 01$ & $-0,03 \%$ & $-0,03 \%$ & $2,76 \%$ ** & $2,92 \%$ ** & $-1,87 \%$ & $0,18 \%$ & $0,10 \%$ & $0,14 \%$ & $2,73 \%{ }^{*}$ & $-1,89 \%$ * & $-1,31 \%$ \\
\hline
\end{tabular}




\begin{tabular}{|c|c|c|c|c|c|c|c|c|c|c|c|}
\hline Date & URM & BE & FR & DE & GR & IT & NL & PT & ES & Core & Non-Core \\
\hline 08/11/01 & $-0,05 \%$ & $1,08 \%$ & $1,84 \%$ & $2,78 \%$ * & $0,01 \%$ & $2,20 \%$ * & $1,42 \%$ & $0,48 \%$ & $3,09 \%$ ** & $1,43 \%$ & $0,28 \%$ \\
\hline 05/12/02 & $-0,05 \%$ & $-1,42 \%$ & $-1,28 \%$ & $-2,88 \%{ }^{*}$ & $-0,76 \%$ & $-2,08 \%{ }^{*}$ & $0,09 \%$ & $0,30 \%$ & $-1,32 \%$ & $1,78 \%$ * & $1,43 \%$ \\
\hline 06/03/03 & $0,10 \%$ & $-1,87 \%$ & $-0,74 \%$ & $-2,40 \%$ & $0,22 \%$ & $-2,72 \%$ ** & $-0,94 \%$ & $0,42 \%$ & $-1,04 \%$ & $-1,32 \%$ & $-0,94 \%$ \\
\hline 05/06/03 & $-0,10 \%$ & $-0,50 \%$ & $-0,94 \%$ & $-1,27 \%$ & $-0,39 \%$ & $-0,31 \%$ & $0,91 \%$ & $0,65 \%$ & $-0,67 \%$ & $-1,44 \%$ & $-0,76 \%$ \\
\hline 01/12/05 & $-0,05 \%$ & $1,12 \%$ & $1,48 \%$ & $1,36 \%$ & $1,05 \%$ & $1,44 \%$ * & $0,72 \%$ & $0,38 \%$ & $1,09 \%$ & $-0,40 \%$ & $-0,16 \%$ \\
\hline 02/03/06 & $0,00 \%$ & $-0,79 \%$ & $-0,99 \%$ & $-1,47 \%$ * & $-1,71 \%$ * & $-1,27 \%$ & $-0,61 \%$ & $-0,34 \%$ & $-0,83 \%$ & $1,26 \%$ & $1,07 \%$ \\
\hline 08/06/06 & $0,00 \%$ & $-2,14 \%$ *** & $-2,98 \%$ *** & $-2,98 \%$ *** & $-0,94 \%$ & $-2,28 \%$ *** & $-4,29 \%$ *** & $-1,52 \%$ ** & $-2,50 \%$ *** & $-0,87 \%$ & $-0,96 \%$ \\
\hline 03/08/06 & $-0,01 \%$ & $-0,50 \%$ & $-0,87 \%$ & $-0,76 \%$ & $-0,11 \%$ & $-0,72 \%$ & $-1,41 \%$ & $0,26 \%$ & $-0,57 \%$ & $-3,00 \%$ *** & $-1,73 \%$ \\
\hline 05/10/06 & $-0,01 \%$ & $0,31 \%$ & $0,58 \%$ & $0,43 \%$ & $1,81 \%$ ** & $0,65 \%$ & $3,25 \%$ *** & $-0,27 \%$ & $0,98 \%$ & $-0,80 \%$ & $-0,21 \%$ \\
\hline 07/12/06 & $0,05 \%$ & $1,08 \%$ & $0,51 \%$ & $0,64 \%$ & $0,83 \%$ & $0,48 \%$ & $0,45 \%$ & $-0,12 \%$ & $0,35 \%$ & $1,24 \%$ & $0,87 \%$ \\
\hline 08/03/07 & $0,02 \%$ & $1,57 \%$ * & $1,24 \%$ & $1,39 \%$ & $1,31 \%$ & $1,30 \%$ & $1,33 \%$ & $0,93 \%$ & $1,95 \%$ ** & $0,76 \%$ & $0,46 \%$ \\
\hline 06/06/07 & $0,01 \%$ & $-1,92 \%$ ** & $-1,69 \%$ * & $-2,47 \%$ *** & $-0,60 \%$ & $-1,46 \%$ * & $-2,12 \%$ ** & $-1,21 \%$ & $-2,60 \%$ *** & $1,47 \%$ & $1,45 \%$ \\
\hline 03/07/08 & $0,02 \%$ & $0,15 \%$ & $1,09 \%$ & $0,72 \%$ & $3,19 \%$ & $0,44 \%$ & $-1,59 \%$ & $-0,29 \%$ & $1,04 \%$ & $-1,96 \%$ * & $-1,39 \%$ \\
\hline 08/10/08 & $0,20 \%$ & $-7,68 \%$ *** & $-6,52 \%$ *** & $-6,10 \%$ *** & $-4,26 \%$ ** & $-5,82 \%$ *** & $-5,40 \%$ *** & $-3,69 \%$ *** & $-5,33 \%$ *** & $0,22 \%$ & $1,10 \%$ \\
\hline 06/11/08 & $0,31 \%$ & $-3,11 \%$ ** & $-6,60 \%$ *** & $-7,13 \%$ *** & $-6,89 \%$ *** & $-5,16 \%$ *** & $-6,70 \%$ *** & $-4,17 \%$ *** & $-6,47 \%$ *** & $-6,30 \%$ *** & $-4,77 \%$ *** \\
\hline 04/12/08 & $0,01 \%$ & $-0,02 \%$ & $-0,19 \%$ & $-0,11 \%$ & $0,49 \%$ & $-1,12 \%$ & $-2,60 \%{ }^{*}$ & $0,27 \%$ & $-0,49 \%$ & $-5,76 \%$ *** & $-5,67 \%$ *** \\
\hline $15 / 01 / 09$ & $0,11 \%$ & $-1,86 \%$ & $-1,87 \%$ & $-2,00 \%$ & $-1,82 \%$ & $-1,92 \%$ & $-2,22 \%$ & $1,04 \%$ & $-0,94 \%$ & $-0,60 \%$ & $-0,21 \%$ \\
\hline 05/03/09 & $0,17 \%$ & $-2,08 \%$ & $-4,06 \%$ *** & $-5,20 \%$ *** & $-1,60 \%$ & $-6,00 \% * * *$ & $-4,42 \%$ *** & $-1,19 \%$ & $-4,60 \%$ *** & $-1,86 \%$ * & $-0,91 \%$ \\
\hline
\end{tabular}




\begin{tabular}{|c|c|c|c|c|c|c|c|c|c|c|c|}
\hline Date & URM & BE & FR & DE & GR & IT & NL & PT & ES & Core & Non-Core \\
\hline 02/04/09 & $-0,24 \%$ & $3,20 \%$ *** & $5,22 \%$ *** & $5,85 \%$ *** & $4,46 \%$ ** & $4,68 \% * * *$ & $4,29 \% * * *$ & $3,38 \% * * *$ & $4,59 \%$ *** & $-3,81 \%$ *** & $-3,35 \%$ *** \\
\hline 07/05/09 & $-0,19 \%$ & $2,34 \%{ }^{*}$ & $-0,99 \%$ & $-1,63 \%$ & $-2,17 \%$ & $-1,43 \%$ & $-0,59 \%$ & $1,74 \%$ & $0,01 \%$ & $4,77 \%$ *** & $4,28 \%$ *** \\
\hline $07 / 04 / 11$ & $-0,13 \%$ & $-0,03 \%$ & $-0,53 \%$ & $-0,55 \%$ & $1,47 \%$ & $-0,37 \%$ & $-0,73 \%$ & $1,12 \%$ & $0,01 \%$ & $-0,09 \%$ & $-0,46 \%$ \\
\hline 07/07/11 & $-0,03 \%$ & $0,88 \%$ & $0,43 \%$ & $0,49 \%$ & $-0,18 \%$ & $-0,24 \%$ & $0,40 \%$ & $1,74 \%$ & $-0,11 \%$ & $-0,34 \%$ & $0,64 \%$ \\
\hline $03 / 11 / 11$ & $0,50 \%$ & $2,39 \%$ ** & $2,65 \%$ ** & $2,72 \%$ *** & $1,79 \%$ & $3,17 \%$ ** & $1,56 \%$ & $2,83 \%$ *** & $1,57 \%$ & $0,67 \%$ & $0,38 \%$ \\
\hline $08 / 12 / 11$ & $-0,11 \%$ & $-2,02 \%$ * & $-2,61 \%$ ** & $-2,08 \%$ * & $-1,36 \%$ & $-4,39 \%$ *** & $-3,15 \%$ *** & $-2,65 \%$ ** & $-2,17 \%$ & $2,45 \% * * *$ & $2,42 \%$ ** \\
\hline 05/07/12 & $0,08 \%$ & $-0,98 \%$ & $-1,22 \%$ & $-0,50 \%$ & $-2,11 \%$ & $-2,06 \%$ & $-0,62 \%$ & $-1,74 \%$ & $-3,06 \%$ ** & $-2,34 \%$ ** & $-2,56 \%$ ** \\
\hline 02/05/13 & $-0,19 \%$ & $0,60 \%$ & $0,01 \%$ & $0,56 \%$ & $0,92 \%$ & $-0,12 \%$ & $0,01 \%$ & $-0,26 \%$ & $-0,18 \%$ & $-0,71 \%$ & $-2,16 \%$ * \\
\hline $07 / 11 / 13$ & $-0,22 \%$ & $-0,75 \%$ & $-0,18 \%$ & $0,39 \%$ & $1,19 \%$ & $-2,09 \%$ & $-0,77 \%$ & $-0,17 \%$ & $-1,02 \%$ & $0,41 \%$ & $0,17 \%$ \\
\hline 05/06/14 & $-0,06 \%$ & $0,25 \%$ & $1,04 \%$ & $0,18 \%$ & $2,82 \%$ & $1,49 \%$ & $0,49 \%$ & $1,01 \%$ & $1,15 \%$ & $-0,21 \%$ & $-0,44 \%$ \\
\hline 04/09/14 & $0,03 \%$ & $1,08 \%$ & $1,62 \%$ & $0,97 \%$ & $1,98 \%$ & $2,76 \%$ & $1,05 \%$ & $1,76 \%$ & $1,98 \%$ & $0,60 \%$ & $1,65 \%$ \\
\hline $16 / 03 / 16$ & $-0,33 \%$ & $0,49 \%$ & $-0,23 \%$ & $0,46 \%$ & $-1,24 \%$ & $-0,20 \%$ & $0,33 \%$ & $2,12 \%$ & $-0,25 \%$ & $1,29 \%$ & $2,15 \%$ * \\
\hline
\end{tabular}

Abnormal returns computed on the day of ECB policy rate modification's announcement on each country index and on the two portfolios grouping them according to their economic

performance. The second column reports the Unexpected Rate Modification (URM). The first group includes Belgium (BE), France (FR), Germany (DE) and the Netherlands (NL), the core economies of the EMU, while the second, the non-core group, encompasses Greece (GR), Italy (IT), Portugal (PT) and Spain (ES). The two horizontal lines separate the three main periods covered into our analysis., the first being the pre-crisis period, the second and the third one the financial crisis period and the sovereign debt crisis period, respectively.

${ }^{* * *}$., ${ }^{* *},{ }^{*}$ indicate respectively $1 \%, 5 \%$, and $10 \%$ significance thresholds. 
It is also interesting to note that there is a common significant reaction to the first two policy manoeuvres, the ones held in fall 2011, while from that time onwards, with the exclusion of a significant reaction of the Spanish market in 2012, ECB appears to lose its influence power on the Eurozone financial markets, at least through its conventional interest rate modification procedure. This contributes evidence to the case of the necessity to recur to unconventional tools in order to fulfil the financial market stabilization task and convey valuable stimuli to the eurozone economies, stuck in a long-standing crisis aggravated by the liquidity trap condition in which the Central Bank found itself.

As from the individual analysis emerged different patterns for core and non-core EMU countries' equity indices, we deepened our examination grouping the stock indices considered in two portfolios.

The results presented in last two columns of Table 4 confirm the inference drawn from the analysis of the individual market reaction: core countries exhibit a more frequent and marked response to policy innovations in the pre-crises and in the financial crisis period; on the contrary, in the last sub-sample, the aggregate reaction of the non-core countries' indices shows the highest significance and magnitude.

This additional evidence allows us to claim that the reaction of equity markets across Eurozone is quite asymmetric, and that it has been so since the start of the currency union.

The relative reaction of the core and non-core groups change in due course as, if before the sovereign crisis the former displays the more frequent and powerful reactions, after it the latter reacts more strongly and more times to the policy stimuli.

Being the equity markets the first recipients of the monetary actions and hence at the base of the transmission chain, it is fundamental that their response to the policy innovation is in line with the authorities' objectives. Thus, an asymmetric reaction is not desirable and is bound to compromise the even reception of the rate modification by the union member countries. The European regulators are called to react and implement the adequate reforms in order to uniform the effects that the Central Bank manoeuvres exert on equity markets, to guarantee that the transmission process starts symmetrically and that, in case of future turmoil, they can use this tool to quell the negative pressure and help to stabilize the markets. 


\section{Conclusions}

"The ultimate objectives of monetary policy are expressed in terms of macroeconomic variables such as output, employment, and inflation. However, the influence of monetary policy instruments on these variables is at best indirect. The most direct and immediate effects of monetary policy actions, such as changes in the Federal funds rate, are on the financial markets; by affecting asset prices and returns, policymakers try to modify economic behaviour in ways that will help to achieve their ultimate objectives. Understanding the links between monetary policy and asset prices is thus crucially important for understanding the policy transmission mechanism" (Bernanke and Kuttner, 2005).

Not only so, but an adequate monetary policy is fundamental to avoid that prerequisites of disastrous crises form on the financial markets (Stein, 2012) and is considered an important tool to fight their possible downturns (Mishkin, 2009). Our empirical study finds that the conventional policy of the ECB has fallen short in both the tasks of maintaining a homogeneous transmission of monetary actions and stabilizing the financial markets.

In particular, the equity indices of core and non-core countries display different reactions, highlighting the inability of interest rate shifts to exert the same influence throughout the eurozone. This is bound to promote an asymmetric unwinding of member countries' business cycles, posing a challenge to the economic policymakers. In the meantime, the conventional monetary policy strategy was deemed by the agents as insufficient to fight the two crises. This motivates the extensive use of extraordinary interventions by the ECB, designed in order to favour the exit from the prolonged recession that was affecting the eurozone. Further research is needed to assess the magnitude and symmetry of unconventional policies impact on EU countries and to study how to make their business cycles more synchronized. 


\section{References}

Angeloni, I., Kashyap A. K, Mojon B. and Terlizzese D.. (2003) Monetary transmission in the euro area: Does the interest rate channel explain it all? Technical report, National Bureau of Economic Research.

Altunbas, Y., Gambacorta, L. and Marques-lbanez, D. (2010). Bank risk and monetary policy. Journal of Financial Stability, 6(3), 121-129.

Bayoumi, T., Eichengreen B. (1993). One money or many? on analyzing the prospects for monetary unification in various parts of the world. Technical report, University of CaliforniaBerkeley, Department of Economics.

Bernanke, B. S., Gertler M. (1995). Inside the black box: The credit channel of monetary policy transmission. The Journal of Economic Perspectives, 9(4): 27-48.

Bernanke, B. S., Kuttner, K. N., (2005) What explains the stock market's reaction to federal reserve policy? The Journal of Finance, 60(3),1221-1257.

Bohl M. T., Siklos, P. L., Sondermann, D. (2008). European stock markets and the ECB's monetary policy surprises. International Finance, 11(2), 117-130.

Brown, S. J., Warner J.B. (1985). Using Daily Stock Returns: The case of event studies. Journal of financial economics, 14(1):3-31.

Bruno, V., Shin, H.S. (2015). Capital flows and the risk-taking channel of monetary policy. Journal of Monetary Economics, 71, 119-132.

Chatelain, J.B., Ehrmann M., Generale A., Martınez-Pages J., Vermeulen P., Worms A. (2003). Monetary policy transmission in the euro area: new evidence from micro data on firms and banks. Journal of the European Economic Association, 1(2-3):731-742.

Ehrmann, M., Gambacorta L., Martinez-Pages J., Sevestre P., and Worms A.. (2003). The effects of monetary policy in the euro area. Oxford Review of Economic Policy, 19(1), 58-72.

loannidis, C., Kontonikas A. (2006). Monetary policy and the stock market: some international evidence. University of Bath and University of Glasgow, UK.

Mackinlay, C. A. (1997). Event studies in economics and finance. Journal of economic literature, 35(1), 13-39.

Mishkin, F. S. (2009). Is Monetary Policy Effective during Financial Crises? The American Economic Review, 99(2), 573-577.

Rigobon R., Sack B. (2004). The impact of monetary policy on asset prices. Journal of Monetary Economics, 51(8), 1553-1575.

Serati, M., Venegoni A.. (2017). The Symmetry of ECB Monetary Policy Impact Under Scrutiny: An Assessment, Liuc Paper Series, n.306, March 2017.

Smets, F. (2013). Financial stability and monetary policy: How closely interlinked?. Sveriges Riksbank Economic Review, 3(121.160).

Stein, J. C. (2012). Monetary Policy as Financial Stability Regulation. The Quarterly Journal of Economics, qjr054. 


